DOI: $10.12737 /$ article_59c214e353d529.17176970

УДК 624.011.14, УДК 624.05

\author{
ЭКСПЕРИМЕНТАЛЬНОЕ ИССЛЕДОВАНИЕ ДИНАМИКИ ОСЛАБЛЕНИЯ УСИЛИЯ \\ УДЕРЖИВАНИЯ ПЕРЕМЕЩАЕМЫХ ДЕРЕВЯННЫХ КОНСТРУКЦИЙ В ФРИКЦИОННЫХ \\ ГРУЗОЗАХВАТНЫХ УСТРОЙСТВАХ \\ аспирант А.И. Бабкин ${ }^{1}$ \\ д-р техн. наук, профессор В.И. Мелехов ${ }^{1}$ \\ канд. техн. наук, доцент А.В. Руденко ${ }^{1}$ \\ 1 - Северный (Арктический) федеральный университет имени М.В. Ломоносова, Россия
}

\begin{abstract}
При применении фрикционных грузозахватных устройств с винтовым приводом для перемещения конструкций из древесины со временем происходит ослабление усилия затяжки винта вследствие реологических особенностей древесины. Ослабление затяжки приводит к уменьшению сил трения, удерживающих перемещаемую конструкцию, что может привести к срыву и падению конструкции. Для обеспечения надежного удерживания грузозахватным устройством деревянной конструкции в течение заданного времени требуется предварительное увеличение усилия затяжки с учетом динамики последующего ослабления. В статье приведено описание экспериментальной установки для исследования скорости ослабления усилия затяжки винтовой струбцины и развития эластической деформации образцов из древесины и фанеры разной толщины со струбцинами разной жесткости. Выявлена зависимость эластической деформации и связанного с ней ослабления усилия затяжки от времени нахождения образцов под нагрузкой. Полученная зависимость имеет общий характер для всех образцов древесины и деревокомпозитных материалов. Для каждого опыта выполнен регрессионный анализ данных и построены графики ослабления усилия затяжки струбцины и развития эластических деформаций. Установлено, что аппроксимация к степенной функции точнее отражает зависимость ослабления усилия затяжки от времени при интервале до 24 часов, чем экспоненциальная функция. Для выявления факторов, влияющих на скорость ослабления усилия затяжки, проведен регрессионный анализ. Выявлена зависимость скорости ослабления усилия затяжки от жесткости струбцины, толщины деревянной конструкции в месте установки грузозахватного устройства и модуля упругости древесины. С увеличением жесткости струбцины и размеров сечения конструкции увеличивается скорость ослабления затяжки. Предложена методика определения коэффициента увеличения усилия предварительной затяжки фрикционных грузозахватных устройств с винтовым приводом для перемещения конструкций из древесины.
\end{abstract}

Ключевые слова: деревянные конструкции, фрикционные грузозахватные устройства, зажимные устройства, контактные элементы, усилие затяжки, реология древесины.

\title{
EXPERIMENTAL STUDY OF THE DYNAMICS OF WEAKENING OF RETENTION FORCE OF MOVA- BLE WOODEN STRUCTURES IN FRICTION GRIPPING DEVICES
}

Post-graduate student A.I. Babkin ${ }^{1}$

DSc (Engineering), Professor V.I. Melekhov ${ }^{1}$

$\mathrm{PhD}$ (Engineering), Associate Professor A.V. Rudenko ${ }^{1}$

1 - Northern (Arctic) Federal University named after M.V. Lomonosov

\begin{abstract}
When using friction gripping device with a screw drive to move designs from wood there is relaxation of tightening force of the screw with time due to rheological characteristics of wood. Weakening of tightening leads to a reduction of friction forces, holding the floating structure, which can lead to failure and drop of structure. To ensure reliable holding of wooden construction by gripping device within the specified time, prior increase in torque taking into
\end{abstract}


account dynamics subsequent weakening is required. The article presents description of experimental setup to study the rate of weakening of the torque of the screw clamp and development of elastic deformation of samples of wood and plywood of different thickness with clamps of different hardness. Dependence of elastic strain and associated weakening of tightening force from time which samples stay under load, is revealed. The dependence has general nature for all the samples of wood and derivative materials. Regression analysis of the data and graphs of weakening the tightness of the clamps and development of elastic deformations is performed for each experiment. It is established that approximation to exponential function reflects the dependence of attenuation of torque settings on time in the interval up to 24 hours more accurately, than exponential function. To identify factors influencing the rate of weakening of the torque, regression analysis is made. The dependence of the rate of weakening of the torque by on stiffness of the clamp, thickness of wooden construction in the place of installation of gripping device and of the modulus of elasticity of wood is revealed. With the increase in rigidity of clamp and size of cross section of structure, weakening speed increases. Method of determining the rate of increase in force of pre-tightening of friction gripping device with screw drive to move wooden structures is suggested.

Keywords: wooden structures, friction gripping devices, clamping devices, contact elements, tightening force, rheology of wood.

Принцип работы фрикционных грузозахватных устройств (ГЗУ) заключается в зажиме кромки перемещаемой конструкции с помощью специальных контактных элементов. Зажимное устройство создает необходимую для удерживания конструкции силу трения $[2,9]$.

При использовании фрикционных ГЗУ с винтовым приводом для перемещения конструкций из древесины со временем происходит ослабление усилия затяжки винта вследствие реологических особенностей древесины. Рассмотрим взаимодействие древесины с контактными элементами зажимного устройства на примере винтовой такелажной струбцины (рис. 1).

При приложении нагрузки к древесине поперек волокон возникают упругие $\varepsilon_{y}$ и пластические $\varepsilon_{\text {п }}$ деформации, которые в реологии принято называть «мгновенными». С течением времени развиваются эластические или «длительные» деформации $\varepsilon_{\ni}[1,6,14,15]$. При снятии нагрузки упругие деформации восстанавливаются быстро, эластические - через определенное время. Суммарная деформация древесины от нагрузки

$$
\varepsilon=\varepsilon_{y}+\varepsilon_{n}+\varepsilon_{\ni} .
$$

Древесина представляет собой «комплекс природных полимеров, что определяет особый характер поведения под нагрузкой» [12]. Связь сложной картины деформирования древесины с еe строением отмечают ряд исследователей $[1,4,6,8$, 12]. Для решения различных задач применяют раз- ные реологические модели. Большинство исследователей описывают модель древесины как упруговязко-эластическое тело или тело Бюргерса. Б.Н. Уголев представляет суммарную деформацию при $\sigma=$ const [12]

$$
\begin{aligned}
& \varepsilon= \frac{\sigma}{E}+\sigma\left(\frac{1}{E_{1}}-\frac{1}{E}\right) e^{-\frac{E t}{E_{1} n}}, \\
& \text { где } E-\text { модуль упругости; } \\
& \\
& \quad E_{1}-\text { мгновенный модуль упругости; } \\
& t-\text { время развития эластической деформа- }
\end{aligned}
$$

ции;

$$
n \text { - время релаксации. }
$$

Е.М. Тюленева рассматривает модель упруго-пластично-эластического тела, которая точнее описывает деформацию древесины при сжатии поперек волокон $[6,10,11]$ :

$$
\varepsilon=\frac{\sigma}{E_{1}}+\frac{\sigma}{E_{3}}+\frac{\sigma}{E_{2}}\left(1-e^{-\frac{E_{2}}{\eta_{2}} t}\right),
$$

где $E_{1}$ - мгновенный модуль упругости;

$$
\begin{aligned}
& E_{2}-\text { модуль упругости второго рода; } \\
& E_{3}-\text { коэффициент пропорциональности }
\end{aligned}
$$
между нагрузкой и пластической деформацией. В [11] предложено называть его «модулем пластической деформации»;

$$
\begin{aligned}
& \eta_{2}-\text { коэффициент эластичности; } \\
& t \text { - время развития эластической деформа- }
\end{aligned}
$$
ции.

В этих моделях эластическая деформация возрастает по экспоненциальному закону и стремится к величине $\frac{\sigma}{E_{2}}$. 


\section{Технологии. Машины и оборудование}

По условиям применения ГЗУ воздействие его контактных элементов не должно приводить к возникновению необратимых деформаций конструкции. Поэтому пластические деформации не рассматриваем, а древесину представляем как упругоэластическое тело. В исследованиях реологии древесины рассматривают стадии ползучести и релаксации [12]. В нашем случае рассмотрена стадия ползучести.

Таким образом, эластические деформации являются причиной ослабления усилия затяжки винтовых зажимных устройств, что приводит к уменьшению сил трения на рабочих поверхностях контактных элементов ГЗУ. Для обеспечения надежного удерживания ГЗУ деревянной конструкции в течение определенного времени требуется предварительное увеличение затяжки с учетом динамики последующего ослабления из-за реологических особенностей древесины. Для этого необходимо знать скорость уменьшения усилия затяжки в течении времени, а также факторов, от которых она зависит.

Рассмотрим это явление на примере зажатия винтовой струбциной образца древесины поперек волокон. После затяжки струбцины с усилием $N$ начальный размер образца $\mathrm{s}_{0}$ (рис. 2) уменьшается до величины $\mathrm{s}_{1}$ в направлении прилагаемой нагрузки. «Мгновенная» деформация $\Delta s_{1}=s_{0}-s_{1}$ является упругой, если не превышен предел прочности на смятие, или упругой и остаточной, если предел прочности превышен.

В течение времени $t$ размер образца уменьшится из-за развития эластических деформаций и достигнет величины $s_{2}$. Величина эластических (или «длительных») деформаций $\Delta s_{2}=s_{1}-s_{2}$.

При этом контактные элементы зажимного устройства сблизятся на величину $\Delta s_{2}$, а усилие зажатия $N$ уменьшится на величину $\Delta N$ :

$$
\Delta N=-\Delta s_{2} C \text {, }
$$

где $\mathrm{C}$ - жесткость зажимного устройства, H/мм, которая определяется как отношение изменения усилия затяжки к изменению расстояния между контактными элементами в результате изменения величины усилия. К корпусам такелажных струбцин, используемых для перемещения дере- вянных конструкций, предъявляются повышенные требования по жесткости $[2,9]$, поэтому в исследовании использовали специальную струбцину с корпусом повышенной жесткости $(8,4$ кН/мм) и стандартные струбцины промышленного изготовления $(0,95$ и 1,54 кН/мм).

Эластическая деформация $\Delta s_{2}$ зависит от величины приложенной нагрузки, толщины образца и модуля упругости материала образца. В рабочей гипотезе приняли, что скорость ослабления усилия затяжки зависит от жесткости зажимного устройства, модуля упругости материала образца, толщины образца и величины приложенной нагрузки.

При моделировании условий работы фрикционных ГЗУ размеры образцов древесины должны превышать по размерам контактные элементы ГЗУ. Механические характеристики и состояние поверхности образцов древесины и деревокомпозитных материалов соответствуют характеристикам материалов, используемых в производстве строительных деревянных конструкций. Усилие затяжки $N$ должно обеспечивать контактное давление от 0,5 до 0,95 расчетного сопротивления смятия $R_{\mathrm{cm}}$ материала образцов древесины.

Для исследования динамики ослабления усилия затяжки зажимного устройства и выявления конструктивных и технологических факторов, влияющих на его величину, разработана методика проведения исследований и создана экспериментальная установка (рис. 3,4 ).

При проведении исследований образец 1 из древесины помещали между контактными элементами 2, которые зажимались винтовой струбциной 3 с электронным динамометром 4. На контактных элементах жестко закреплены стойки, на верхней крепятся индикаторы перемещения 5 часового типа, а на нижней - регулируемые по высоте контактные площадки. Индикаторы расположены симметрично относительно оси контактных элементов.

Для обеспечения начального контакта между контактными элементами и поверхностью образца винт струбцины затягивали с усилием 0,10,2 кН. После этого индикаторы перемещения уста- 
навливали на «0», запускали компьютерную программу View300 для автоматической регистрации показаний электронного динамометра, фиксирующего усилие затяжки в режиме реального времени в течение 5 минут. Программа позволяет фиксировать максимальную нагрузку, которая является начальной нагрузкой, а время максимальной нагрузки считается временем начала опыта (рис. 5). По истечении 5 минут измерения проводили с помощью

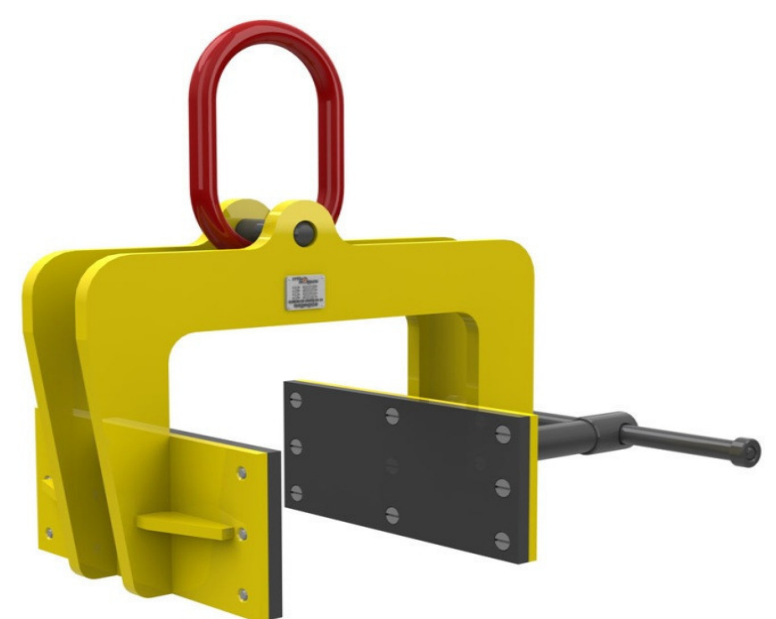

Рис. 1. Винтовая такелажная струбцина для сэндвич-панелей измерительного терминала динамометра. Интервал измерений составлял от 0,5-1 минуты в начале опыта, когда скорость ослабления нагрузки максимальная, до 240 минут. В каждом опыте проводили 18 измерений, время опыта 24 часа. После опыта на образцах отмечалось место установки контактных элементов для последующего определения модуля упругости материала образца в соответствии с ГОСТ 16483.25-73 [3].

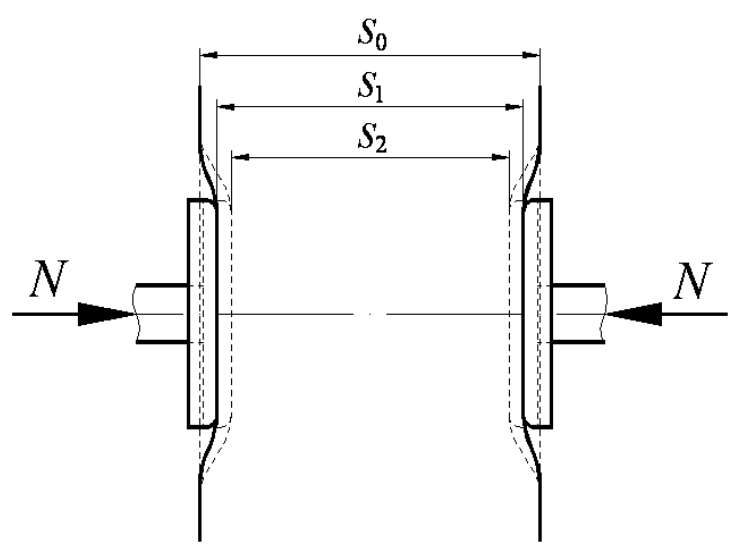

Рис. 2. Деформации образца древесины при зажатии струбциной

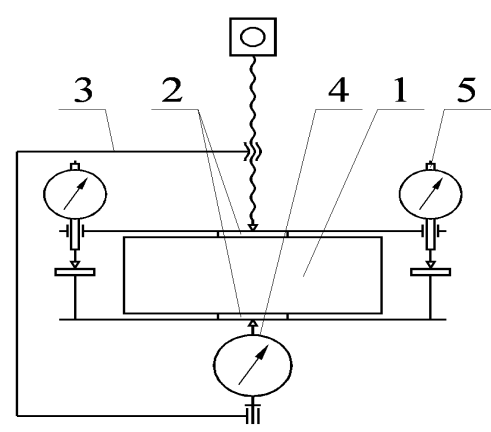

Рис. 3. Схема экспериментальной установки:

1 - образец древесины;

2 - контактные элементы;

3 - винтовая струбцина;

4 - динамометр ДЭП3-1Д-5У-1; 5 - индикатор ИЧ $10 \mathrm{MH}$

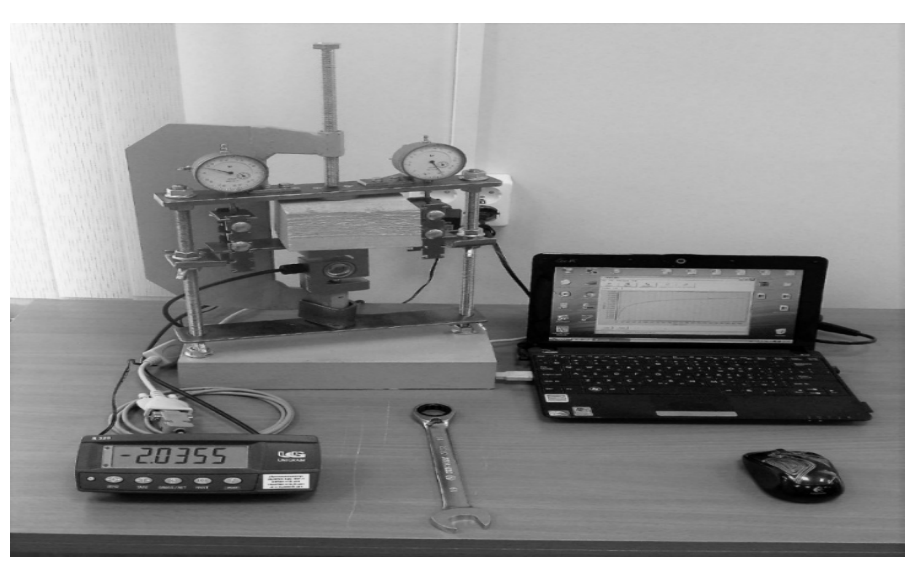

Рис. 4. Общий вид экспериментальной установки 


\section{Технологии. Машины и оборудование}

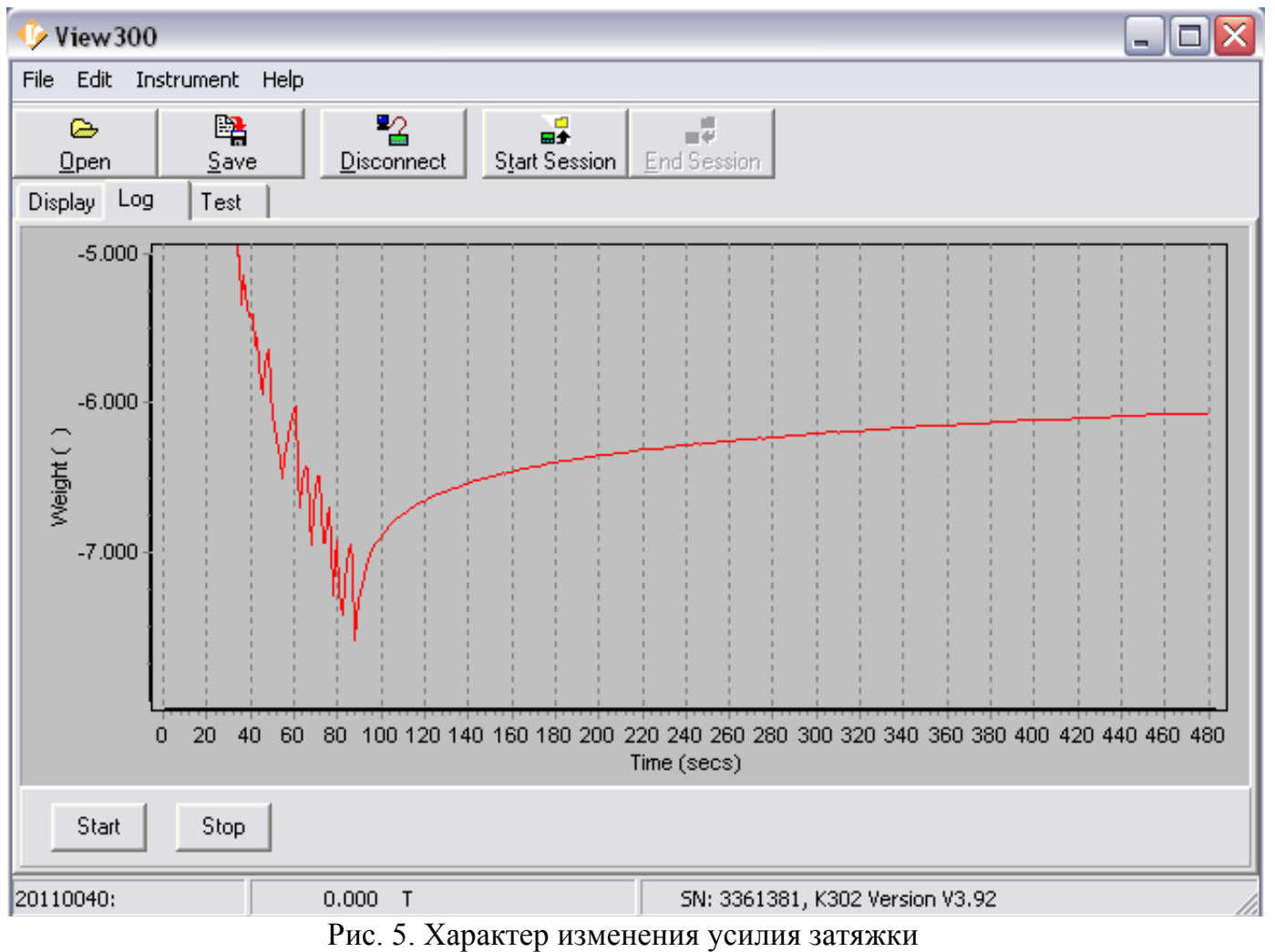

Образцы 90×120 мм из древесины сосны и ели толщиной 18,36 и 58 мм, фанеры ФК 2/4 НШ толщиной 16 и 32 мм и клееной древесины сосны толщиной 54 мм. Влажность образцов 10-12\%.

Исследования проводили на трех струбцинах разной жесткости с комплектом стальных контактных элементов диаметром 40 мм, толщиной 6 мм. Усилие зажатия контактных элементов обеспечивалось затяжкой винта струбцины на величину, обеспечивающую давление от 1 до 1,8 МПа.

Деформацию измеряли с помощью двух индикаторов перемещения ИЧ $10 \mathrm{MH}$. Первоначальное измерение мгновенной деформации выполняли сразу после приложения нагрузки. Дальнейшее развитие деформации является эластической стадией.

Все результаты измерений усилия затяжки и деформации заносили в файл формата Excel. По результатам опытов построены графики ослабления усилия затяжки по отношению к первоначальной (рис. 6) и эластической деформации (рис. 7) и вы- полнен регрессионный анализ. Получены уравнения регрессии степенной функции: $N / N_{0}=a_{0} t^{a_{1}}$; $\Delta s_{9 л}=a_{0} t^{a_{1}}$, где $N / N_{0}$ - отношение текущего усилия затяжки к первоначальному, $\Delta s_{\text {эл }}$-абсолютная эластическая деформация. Адекватность моделей по критерию Фишера составила от 0,02 до 0,009.

Принято, что эластическая деформация подчиняется экспоненциальному закону $\Delta s_{\text {эл }}=$ $a_{0}\left(1-e^{-a_{1} t}\right)$ [12]. Адекватность экспоненциальных моделей по Фишеру составила от 0,3 до 0,05 . В ходе исследований установлено, что приведение к степенному виду $\Delta s_{9 л}=a_{0} t^{a_{1}}$ точнее отражает зависимость эластической деформации от времени (рис. 7) на отрезке от 0,5 до 24 часов.

Анализ полученных зависимостей отражает влияние жесткости струбцины и толщины образца древесины на динамику ослабления затяжки. С увеличением жесткости струбцины и толщины образцадревесины увеличивается скорость ослабления усилия затяжки. 
Технологиии. Машины и оборудование

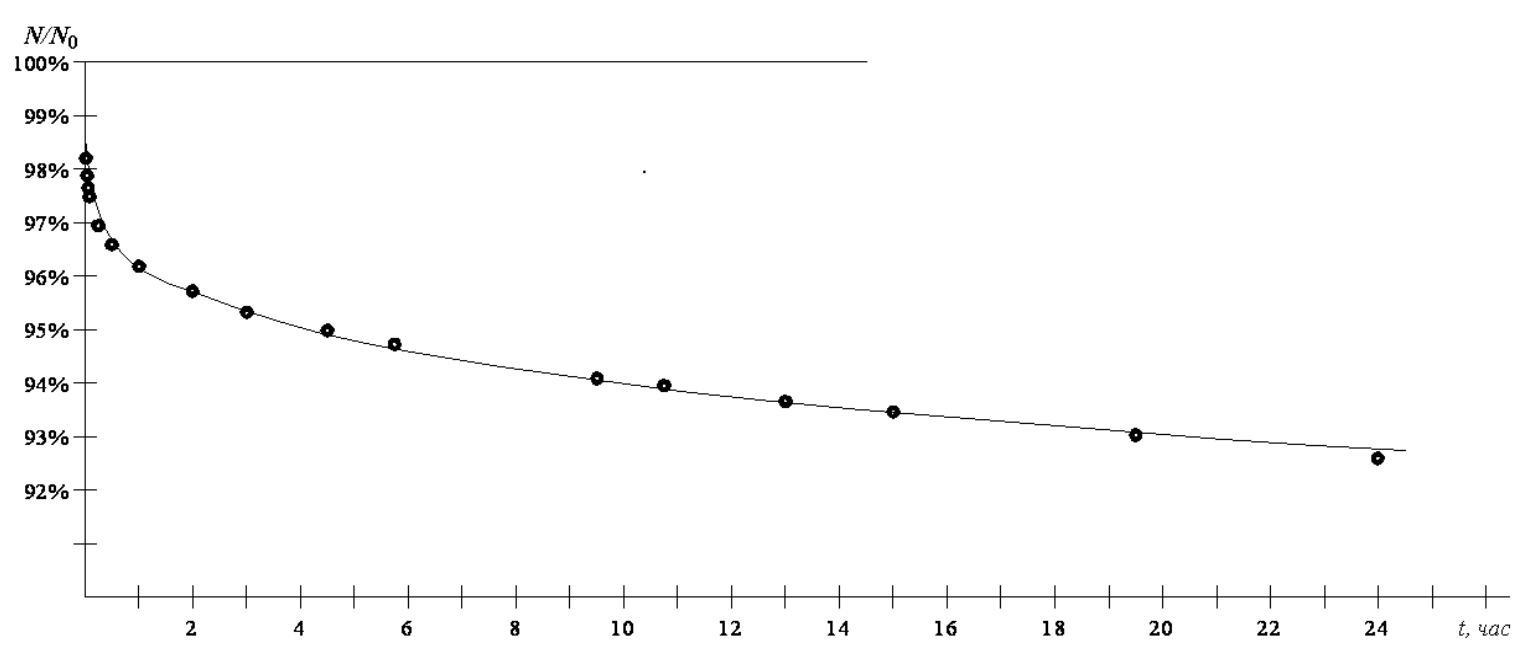

Рис. 6. Характер изменения усилия затяжки

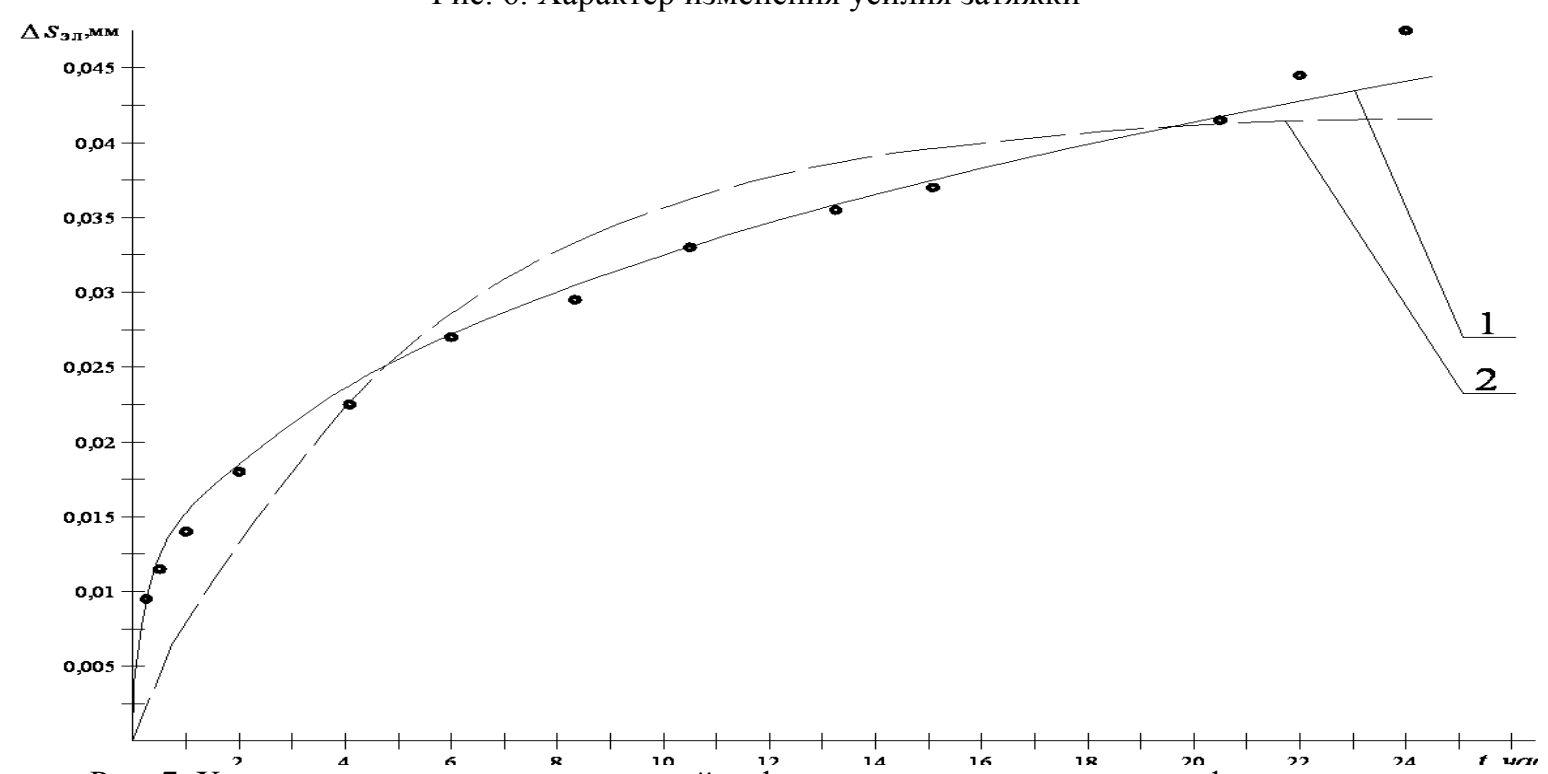

Рис. 7. Характер нарастания эластической деформации и аппроксимация к функции вида:

$$
1-\Delta s_{э л}=a_{0} t^{a_{1}} ; 2-\Delta s_{э л}=a_{0}\left(1-e^{-a_{1} t}\right)
$$




\section{Технологии. Машины и оборудование}

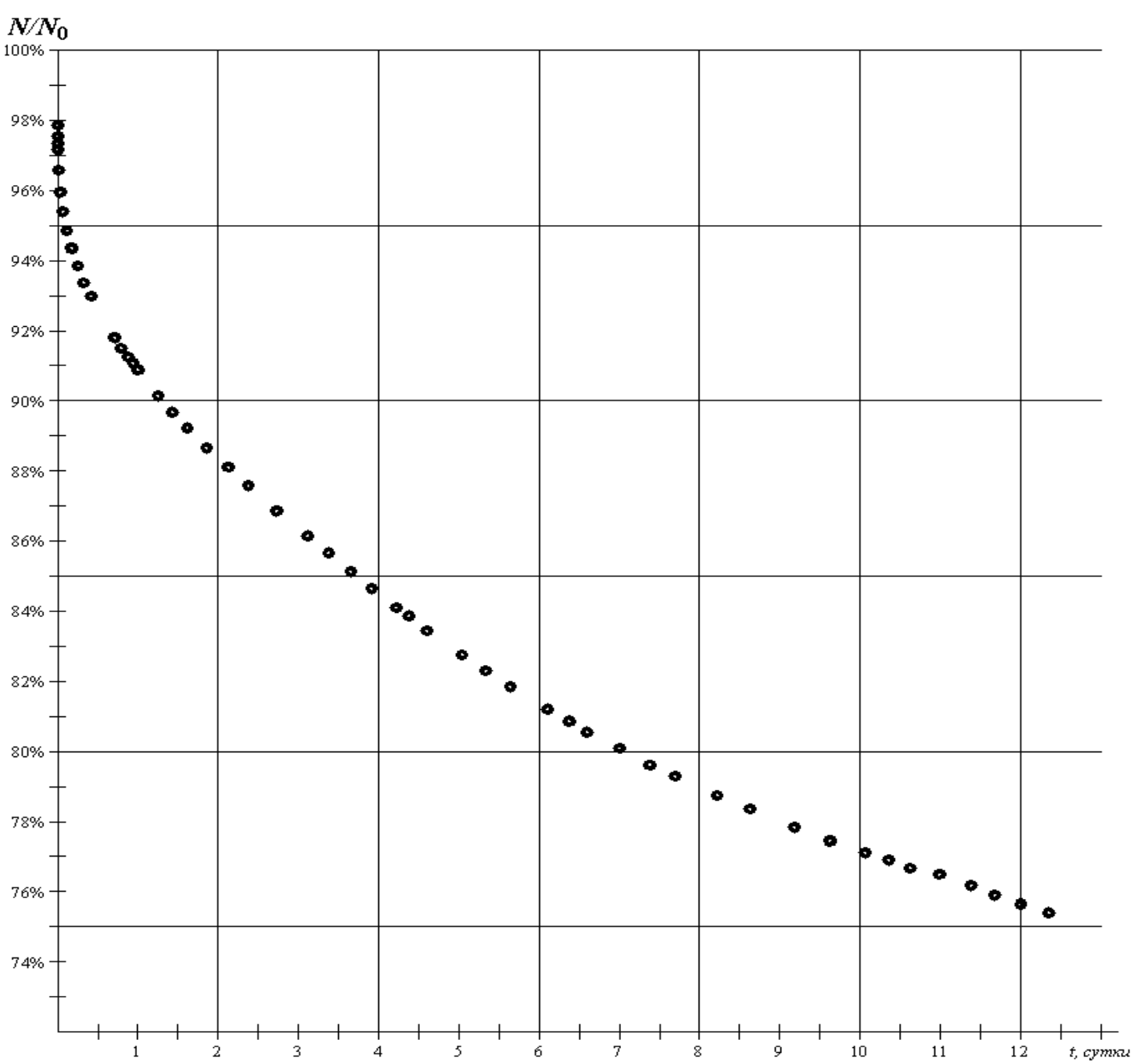

Рис. 8. Характер изменения усилия затяжки в течение 12,5 суток

Согласно [11], «развитие деформации во времени останавливается при 100-110 часах». Однако в нашем случае для образца толщиной 16 мм со струбциной жесткостью 8,4 кН/мм рост эластической деформации остановился через 50-60 часов, а для образца толщиной 36 мм со струбциной жесткостью 0,95 кН/мм при временном интервале 12,5 суток прекращения роста деформации не выявлено (рис. 8).

Таким образом, при длительной выдержке под нагрузкой прослеживается зависимость времени прекращения развития эластической деформации от толщины образца и жесткости зажимного устройства.

Экспериментальные данные сформированыв две матрицы наблюдений $65 \times 5$ [5]. От каждого опыта для матрицы взято по 5 измерений, ближай- ших к значениям 1, 2, 5, 10 и 24 часа. Получено уравнение регрессии зависимости ослабления усилия затяжки $[5,7]$

$$
\Delta N=0,885 \frac{E^{0,0525}}{C^{0,0346} S^{0,0579} t^{0,0156}}
$$

где $C$ - жесткость струбцины;

$s$ - толщина образцов из древесины;

$E$ - модуль упругости древесины;

$t$ - время измерения.

Значения статистики критерия для коэффициентов:

$$
\begin{array}{ll}
T_{0}=16,9236 ; & T_{C}=-10,8176 ; T_{s}=-8,3825 ; \\
T_{E}=6,7646 ; & T_{t}=-5,5393 ;
\end{array}
$$

Критическое значение для уровня значимости $\alpha=0,01, n-m=61$ :

$$
t_{1-\frac{\alpha}{2}}(n-m)=2,3901 .
$$


Фактор первоначального усилия затяжки $N_{0}$ оказался незначимым.

Проверка адекватности по критерию Фишера:

$F=\frac{Q_{n}}{n-m} \cdot \frac{\sum_{i=1}^{n}\left(r_{i}-1\right)}{Q_{p}}=0,2308<F_{\kappa p}=3,649$,

что подтверждает адекватность модели.

Полученную зависимость (5) можно использовать для определения коэффициента увеличения усилия предварительной затяжки

$$
K_{n 3}=\frac{1}{\Delta N}=1,13 \frac{C^{0,0346} s^{0,0579} t^{0,0156}}{E^{0,0525}} .
$$

Эта зависимость является универсальной для любого периода времени, однако в целях безопасности при использовании ГЗУ в короткие отрезки времени (10-20 минут) следует использовать величину $t$ не менее 1 часа во избежание угрозы срыва и падения перемещаемой конструкции в результате непредвиденных задержек при транспортировке.

Поэтому для практического применения рекомендуется использовать коэффициент увеличения усилия предварительной затяжки при транспортировке продолжительностью до 1 часа

$$
K_{n 31}=1,13 \frac{C^{0,0346} S^{0,0579}}{E^{0,0525}}
$$

и коэффициент увеличения усилия предварительной затяжки при транспортировке продолжительностью свыше 1 часа

$$
K_{n 3}=K_{n 31} t^{0,0156}
$$

Аналогично выполнен регрессионный анализ для относительной эластической деформации $[5,7]$ :

$$
\varepsilon_{\ni}=1355,6 \frac{N_{0}^{0,4784} t^{0,3414}}{C^{0,1557} S^{0,4046} E^{1,2428}},
$$

где $N_{0}$ - начальное усилие затяжки струбцины.

Значения статистики критерия для коэффициентов:
$T_{0}=5931,6 ; \quad T_{N_{0}}=5,9022 ; \quad T_{C}=-10,3376 ;$ $T_{s}=-13,1816 ; \quad T_{E}=-36,4064 ; \quad T_{t}=28,0994 ;$

Критическое значение для уровня значимости $\alpha=0,01, n-m=60$ [7]:

$$
t_{1-\frac{\alpha}{2}}(n-m)=2,391 .
$$

Проверка адекватности по критерию Фишера:

$F=\frac{Q_{n}}{n-m} \cdot \frac{\sum_{i=1}^{n}\left(r_{i}-1\right)}{Q_{p}}=0,0845<F_{\kappa p}=3,649$, что подтверждает адекватность модели.

\section{Выводы:}

1. Установлена зависимость эластической деформации и связанного с ней ослабления усилия затяжки от времени нахождения образцов древесины под нагрузкой. Полученная зависимость имеет общий характер для всех образцов древесины и деревокомпозитных материалов.

2. Максимальная скорость развития эластической деформации и связанного с ней ослабления усилия затяжки наблюдается непосредственно после приложения нагрузки и постепенно уменьшается. Через 20-40 минут меняется характер зависимости, и ее график становится более пологим.

3. Значимыми факторами ослабления усилия затяжки являются жесткость струбцины и толщина поперечного сечения деревянной конструкции в месте установки ГЗУ. С увеличением жесткости струбцины и размеров сечения конструкции ослабление затяжки происходит быстрее. Это ограничивает применение винтовых такелажных струбцин для перемещения деревянных конструкций больших размеров.

4. Предложенная методика позволяет определить коэффициент увеличения усилия предвари-

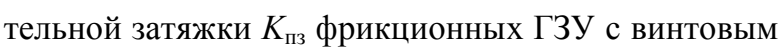
приводом для перемещения конструкций из древесины при длительности операции транспортировки до 1 часа по формуле (7) и свыше - по формуле (8). 


\section{Технологии. Машины и оборудование}

\section{Библиографический список}

1. Белянкин Ф.П., Яценко В.Ф. Деформативность и сопротивляемость древесины как упруго-вязкопластического тела - Киев: Изд-во Акад. наук УССР, 1957. - 200 с.

2. Вайнсон А.А., Андреев А.Ф. Специализированные крановые грузозахватные устройства для штучных грузов. - М.: Машиностроение, 1972. - 200 с.

3. ГОСТ 16483.25-73: Древесина. Метод определения модуля упругости при сжатии поперек волокон. - М.: ИПК Издательство стандартов, 1999. - 5 с.

4. Дунаев В.Ф., Мелехов В.И., Захаров М.В. Закономерность изменения механических свойств древесины во времени при удержании реакции // Лесной журнал, 2014, №2. с. 75-85.

5. Евдокимов Ю.А., Колесников В.И., Тетерин А.И. Планирование и анализ экспериментов при решении задач трения и износа. - М.: Наука, 1980. - 228 с.

6. Курицын В.Н., Тюленева Е.М. Экспериментальное уточнение реологической модели древесины // Лесной журнал, 2009, №5. с. 104-109.

7. Математическая статистика / Под ред. В.С. Зарубина, А.П. Крищенко. М.: МГТУ им. Н.Э. Баумана, 2001. $424 \mathrm{c}$.

8. Мелехов В.И., Подольская В.Л. К вопросу о процессе деформации и деструкции древесины при сжатии поперек волокон // Лесной журнал, 1999, №2-3. с. 120-124.

9. Морозов А.С., Руденко А.В., Родичкин С.А. Компьютерное исследование силовых характеристик фрикционного грузозахватного устройства // Развитие Северо-Арктического Региона: Проблемы и решения. Материалы научной конференции профессорско-преподавательского состава, научных сотрудников и аспирантов САФУ им. М.В. Ломоносова. 2016. Издательство САФУ. с. 1362-1365.

10. Тюленева Е.М. Уточнение реологической модели древесины // Хвойные бореальной зоны, XXV, № 1-2, 2008. c. $179-183$.

11. Тюленева Е.М. Остаточные деформации в древесине // Лесной вестник, 2014, №2. с. 70-74.

12. Уголев Б.Н. Деформативность древесины и напряжения при сушке. - М.: Лесная промышленность, 1971. $176 \mathrm{c}$.

13. Уголев Б.Н. Древесиноведение и лесное товароведение: Учебник. - М.: ГОУ ВПО МГУЛ, 2007. - 351 с.

14. Hoffmeyer P., Davidson R.W. Mechano-sorptive creep mechanism of wood in compression and bending // Wood Science and Technology, September 1989, Vol. 23(3), pp 215-227.

15. Hunt D.G. The mechano-sorptive creep susceptibility of two softwoods and its relation to some other materials properties // Journal of Materials Science, June 1986, Vol. 21, Issue 6, pp 2088-2096.

\section{References}

1. Belyankin F.P., Yatsenko V.F. Deformativnost' $i$ soprotivlyaemost' drevesiny ka kuprugo-vyazko-plasticheskogo tela [Deformability and resilience of wood as elastic-visco-plastic body].Kiev, 1957, 200 p. (In Russian)

2. Vaynson A.A., Andreev A.F. Spetsializirovannye kranovye gruzozakhvatnye ustroystva dlya shtuchnykh gruzov [Specialized crane load gripping devices for piece freights]. Moscow, 1972, 200p. (In Russian)

3. GOST 16483.25-73: Drevesina. Metod opredeleniya modulya uprugosti pri szhatii poperek volokon [State Standard 16483.25-73.Wood. A method of definition of the module of elasticity at compression across fibers]. Moscow, 1999. -5 p. (In Russian)

4.Dunaev V.F., Melekhov V.I., Zakharov M.V. Zakonomernost' izmeneniya mekhanicheskikh svoystv drevesiny vo vremeni pri uderzhanii reaktsii [Regularity of change of mechanical properties of wood in time at reaction deduction]. Lesnoy zhurnal [Forest magazine]. 2014, no. 2, p. 75-85. (In Russian) 
5. EvdokimovYu.A., Kolesnikov V.I., Teterin A.I. Planirovanie i analiz eksperimentov pri reshenii zadach treniya iiznosa [Planning and the analysis of experiments at the solution of problems of friction and wear]. Moscow, 1980, $228 \mathrm{p}$. (In Russian)

6. Kuritsyn V.N., Tyuleneva E.M. Eksperimental'noe utochnenie reologicheskoy modeli drevesiny [Experimental specification of rheological model of wood].Lesnoy zhurnal [Forest magazine]. 2009, no. 5, p. 104-109. (In Russian)

7. Matematicheskaya statistika / Pod red. V.S. Zarubina, A.P. Krishchenko [Mathematical statistics]. Moscow, 2001, 424 p. (In Russian)

8. Melekhov V.I., Podol'skaya V.L. K voprosu o protsesse deformatsiii destruktsii drevesiny pri szhatii poperek volokon [To a question of process of deformation and destruction of wood at compression across fibers]. Lesnoy zhurnal [Forest magazine]. 1999, no. 2-3, p. 120-124. (In Russian)

9. Morozov A.S., Rudenko A.V., Rodichkin S.A. Komp'yuternoe issledovanie silovykh kharakteristik friktsionnogo gruzozakhvatnogo ustroystva [Computer research of power characteristics of the frictional load gripping device]. Materialy nauchnoy konferentsi iprofessorsko-prepodavatel'skogo sostava, nauchnykh sotrudnikov i aspirantov SAFU im. M.V. Lomonosova [Materials of a scientific conference of the faculty, research associates and graduate students of SAFU of M. V. Lomonosov]. Arkhangelsk, 2016, p. 1362-1365 (In Russian)

10. Tyuleneva E.M. Utochnenie reologicheskoy modeli drevesiny [Specification of rheological model of wood].Khvoynyeboreal'noyzony [Coniferous boreal zone], XXV, no 1-2, 2008. p. 179-183.(In Russian)

11. Tyuleneva E.M.Ostatochnye deformatsii $v$ drevesine [Residual deformations in wood].Lesnoy vestnik [Forest messenger]. 2014, №2,p. 70-74. (In Russian)

12. Ugolev B.N. Deformativnost' drevesiny i napryazheniya pri sushke [Deformability of wood and tension when drying]. Moscow, 1971, 176 p. (In Russian)

13. Ugolev B.N.Drevesinovedenie i lesnoe tovarovedenie [Wood science and forest merchandizing].Moscow, 2007, 351p. (In Russian)

14. Hoffmeyer P., Davidson R.W. Mechano-sorptive creep mechanism of wood in compression and bending. Wood Science and Technology, September 1989, Vol. 23(3), pp 215-227.

15. Hunt D.G. The mechano-sorptive creep susceptibility of two softwoods and its relation to some other materials properties. Journal of Materials Science, June 1986, Vol. 21, Issue 6, pp 2088-2096.

\section{Сведения об авторах}

Бабкин Александр Иванович - старший преподаватель кафедры проектирования подъемно-транспортного и технологического оборудования, ИСМАРТ, филиал ФГАОУВО Северный (Арктический) федеральный университет им. М.В.Ломоносова в г. Северодвинске, г. Северодвинск, Российская Федерация; e-mail: a.babkin@narfu.ru

Мелехов Владимир Иванович - профессор кафедры технологии лесозаготовительных и деревообрабатывающих производств, Высшая инженерная школа, ФГАОУВО Северный (Арктический) федеральный университет им. М.В.Ломоносова, доктор технических наук, профессор, г. Архангельск, Российская Федерация; е-таil: v.melekhov@narfu.ru

Руденко Александр Васильевич - заведующий кафедрой проектирования подъемно-транспортного и технологического оборудования, ИСМАРТ, филиал ФГАОУВО Северный (Арктический) федеральный университет им. М.В.Ломоносова в г. Северодвинске, кандидат технических наук, доцент, г. Северодвинск, Российская Федерация; еmail: a.rudenko@narfu.ru

\section{Information about authors}

Babkin Aleksandr Ivanovich - Teacher of Department of design of hoisting-and-transport and processing equipment, ISMART, Branch of Northern (Arctic) Federal University named after M.V. Lomonosov in Severodvinsk, Severodvinsk, Russian Federation; e-mail: a.babkin@narfu.ru; 
Melekhov Vladimir Ivanovich - Professor of Department of technology of logging and wood working productions, Higher Engineering School, Northern (Arctic) Federal University named after M.V. Lomonosov, Ds in Engineering, Professor, Arkhangelsk, Russian Federation; e-mail: v.melekhov@narfu.ru;

Rudenko Aleksandr Vasilevich - Head of Department of design of hoisting-and-transport and processing equipment, ISMART, Branch of Northern (Arctic) Federal University named after M.V. Lomonosov in Severodvinsk, PhD in Engineering, Associate Professor, Severodvinsk, Russian Federation; e-mail: a.rudenko@narfu.ru

DOI: $10.12737 /$ article_59c215c32fe8d8.24740444

УДК 631.312 .4

\section{МНОГОФУНКЦИОНАЛЬНЫЙ ЛЕСНОЙ ПЛУГ}

доктор технических наук, профессор И.М. Бартенев ${ }^{1}$

кандидат технических наук, М.Н. Лысыч ${ }^{1}$

кандидат технических наук, доцент М.Л. Шабанов ${ }^{1}$

кандидат технических наук, И.Е. Донцов ${ }^{1}$

1 - ФГБОУ ВО «Воронежский государственный лесотехнический университет имениГ.Ф. Морозова»,

г. Воронеж, Российская Федерация

Основная подготовка почвы является важным фактором в обеспечении высокой приживаемости и сохранности культурных растений. Ее целью является рыхление почвы на заданную глубину, при этом также необходимо обеспечить сдерживание роста сорной растительности в прилегающих к рядкам культур полосах. В зависимости от почвенных условий подготовка может заключаться в нарезке одно- или двухотвальных борозд (дренированные почвы) и в образовании микроповышений (временно переувлажненные почвы). Для этих целей в настоящее времяиспользуют плуги: ПКЛ-70, ПРЛ-70, ПЛ-1, ПЛМ-1,5А, ПДВ-1,5, ПЛ-2-50, ПЛД-1,2 и др. Их общим недостатком является способность выполнять только одну операцию. Большое разнообразие используемой почвообрабатывающей техники и ее невысокая эффективность подтверждает актуальность задачи создания многофункционального орудия блочно-модульной конструкции. Это позволит эффективно производить одним орудием основную подготовку почвы в разнообразных условиях. В статье приводится описание конструкции и основные варианты компоновки многофункционального плуга. Путем простых переналадок, осуществляемых на месте, плуг может быть адаптирован для основной подготовки почвы на вырубках с дренированными и временно переувлажненными почвами. Также возможно изменять расстояние между корпусами плуга в соответствии с заданными междурядьями и переставлять их для работы «всвал» или «вразвал». Смоделирован процесс работы орудия в условиях нераскорчеванной вырубки. Имитационный эксперимент подтвердил высокую работоспособность плуга, которая обеспечиваетсяза счет наличия предохранительных рекуперирующих устройств. Замена в лесохозяйственном предприятии набора различных плугов одним многофункциональным плугом позволит снизить общую металлоемкость парка почвообрабатывающих орудий почти в 4 раза.

Ключевые слова: почва, почвообрабатывающее орудие, блочно-модульная компоновка, лесовосстановление, технология. 